\title{
High-throughput technologies for sunflower oil improvement
}

\author{
A.I. Chernova*, E.U. Martynova \\ Skolkovo Institute of Science and Technology, Moscow, Russia
}

DOI 10.18699/ICG-PlantGen2019-74

(c) Autors, 2019

* e-mail: alin.chernova@gmail.com

\begin{abstract}
Cultivated sunflower in one of the key plants used by humans. Nowadays sunflower is planted mainly for the seed oil. It takes position number four on the global seed oil market. Selection of hybrids with increased oil content and changed oil properties is one of the basic directions in sunflower hybrid breeding. Due to the extensive climate change and the growing human population, selection time became a serious bottleneck on the way to the production of new cultivars. High-throughput genotyping and phenotyping technologies can push forward sunflower breeding and help reducing time required for the selection process.

Key words: sunflower; oil composition; marker-assisted selection; genomic selection; phenotyping technologies.
\end{abstract}

\section{Introduction}

Sunflower is one of the most important oilseed crops, which takes position four in the global production of vegetable oil after palm, soybean, and rapeseed. It is known that oilseed content is influenced by both environmental conditions and genetic factors (Rauf et al., 2017). That's why production of selection hybrids with changed oil properties is one of the key objectives of oilseed crop breeding (Jocic', Miladinovic', and Kaya 2015). Since the pioneering work of V.S Pustovoit in the 1960s high seed oil content has become one of the principal directions in sunflower breeding (Vear 2016). The second crucial sunflower oil characteristic is seed oil composition which was altered during the transformation of sunflower from the wild-type to domesticated oilseed crop (Putt 1997; Burke, Knapp, and Rieseberg 2005). The main components of sunflower oil are triglycerides (about 95\%), which are made up of three fatty acids (FAs) attached to glycerol by ester bonds. Nutritional and technical properties of sunflower oil are determined by the fatty acids (FA) composition (Garcés et al., 2009). Genetic markers associated with certain oil phenotypes can be implemented in marker-assisted (MAS) or genomic selection (GS) in order to speed up the selection of sunflower cultivars with desirable oil characteristics (Dimitrijevic and Horn 2018).

\section{Genetic markers for sunflower}

Before NGS sequencing became widely available, sunflower genotyping and mapping were performed using RAPD (Rieseberg et al., 1993), RFLP (Lai et al., 2005), AFLP (Gedil et al., 2001) and SSR markers (Tang et al., 2003). The availability of SNP-based markers revolutionized sunflower genetics. The first SNP study for sunflower was performed in 2005, 243 SNPs were mapped (Lai et al., 2005). This study was followed up by the design of Infinium Beadchip containing 9,480 SNPs (Bachlava et al., 2012) and 25K SNP array (Livaja et al., 2016).

Another step was made by the implementation of genome complexity reduction techniques such as RAD sequencing (Bowers et al., 2012; Talukder et al., 2014) and GBS sequenc- ing (Celik et al., 2016). Such approaches made it possible to avoid expensive whole genome sequencing providing at the same time more opportunities compared to microarray technologies since the former can obtain short sequences-reads, covering the major part of the genome. Sunflower genome full assembly published in 2017 (Badouin et al., 2017) made it possible to perform large-scale genome-wide association studies (GWAS).

\section{Phenotyping technologies}

Efficient genotyping technologies should run side by side with efficient oil phenotyping technologies. For a long period of time the most common ways for plant oil phenotyping were gas chromatography-mass spectrometry (GS-MS) or gas chromatography-flame ionization detection (GC-FID) methods (Li-Beisson et al., 2010).

As an alternative to this technique, NMR spectroscopy (Popescu et al., 2015) may be used. Another method combining the advantages of fast high-resolution chromatographic separation with high-sensitivity and selectivity of massspectrometric detection is UPLC-MS. This method was first proposed to be used for plant fatty acid profiling in Arabidopsis thaliana and diatoms (Bromke et al., 2013, 2015). Later, this method was validated for sunflower lipid oil profiling (Chernova et al., 2019).

\section{Genome-wide association studies}

High quality phenotype and genotype data can be used for genome wide association studies (GWAS). This analysis is a powerful tool for understanding the genetic content of complex traits. GWAS was successfully implemented to many plant species including sunflower. In the case of sunflower, GWAS gave a new insight into flowering time (Bonnafous et al., 2018), male fertility restoration (Goryunov et al., 2019), seedling growth (Masalia et al., 2018), plasticity of oil yield for combined abiotic stresses (Mangin et al., 2017), basal and apical branching (Nambeesan et al., 2015), flower morphological traits (Dowell et al., 2019), and others. 


\section{Conclusions}

According to the points discussed above, it can be concluded that NGS high-throughput genotyping can be combined with high-throughput molecular phenotyping technologies to perform GWAS in order to find significant associations between valuable oil characteristics and the genotype. Such associations can be implemented in sunflower genomic selection and push forward sunflower breeding strategies.

\section{References}

Bachlava E., Taylor C.A., Tang S., Bowers J.E., Mandel J.R., Burke J.M., Knapp S.J. SNP Discovery and development of a high-density genotyping array for sunflower. PLOS ONE. 2012;7(1):e29814. https:// doi.org/10.1371/journal.pone.0029814.

Badouin H., Gouzy J., Grassa C.J., Murat F., Staton S.E., Cottret L., Lelandais-Brière C. et al. The sunflower genome provides insights into oil metabolism, flowering and asterid evolution. Nature. 2017;546(7656):148-52. https://doi.org/10.1038/nature22380.

Bonnafous F., Fievet G., Blanchet N., Boniface M.-C., Carrère S., Gouzy J., Legrand L. et al. Comparison of GWAS models to identify non-additive genetic control of flowering time in sunflower hybrids. TAG. Theoretical and Applied Genetics. Theoretische Und Angewandte Genetik. 2018;131(2):319-32. https://doi.org/10.1007/ s00122-017-3003-4.

Bowers J.E., Bachlava E., Brunick R.L., Rieseberg L.H., Knapp S.J., Burke J.M. Development of a 10,000 locus genetic map of the sunflower genome based on multiple crosses. G3: Genes, Genomes, Genetics. 2012;2(7):721-729. https://doi.org/10.1534/g3.112. 002659.

Bromke M.A., Giavalisco P., Willmitzer L., Hesse H. Metabolic analysis of adaptation to short-term changes in culture conditions of the Marine Diatom Thalassiosira Pseudonana. PLOS ONE. 2013;8(6): e67340. https://doi.org/10.1371/journal.pone.0067340.

Bromke M.A., Hochmuth A., Tohge T., Fernie A.R., Giavalisco P., Burgos A., Willmitzer L., Brotman Y. Liquid chromatography high-resolution mass spectrometry for fatty acid profiling. The Plant Journal. 2015;81(3):529-536. https://doi.org/10.1111/tpj.12739.

Burke J.M., Knapp S.J., Rieseberg L.H. Genetic consequences of selection during the evolution of cultivated sunflower. Genetics. 2005; 171(4):1933-1940. https://doi.org/10.1534/genetics.104.039057.

Celik I., Bodur S., Frary A., Doganlar S. Genome-wide SNP discovery and genetic linkage map construction in sunflower (Helianthus Annuus L.) using a genotyping by sequencing (GBS) approach. Mol Breed. 2016;36(9):133. https://doi.org/10.1007/s11032-016-0558-8.

Chernova A., Mazin P., Goryunova S., Goryunov D., Demurin Y., Gorlova L., Vanyushkina A. et al. Ultra-performance liquid chromatography-mass spectrometry for precise fatty acid profiling of oilseed crops. PeerJ. 2019;7(March):e6547. https://doi.org/10.7717/ peerj.6547.

Dimitrijevic A., Horn R. Sunflower hybrid breeding: From markers to genomic selection. Frontiers in Plant Sci. 2018;8. https://doi. org/10.3389/fpls.2017.02238.

Dowell J.A., Reynolds E.C., Pliakas T.P., Mandel J.R., Burke J.M., Donovan L.A., Mason C.M. Genome-wide association mapping of floral traits in cultivated sunflower (Helianthus Annuus). The Journal of Heredity. 2019;110(3):275-286. https://doi.org/10.1093/ jhered/esz013.

Garcés R., Martínez-Force E., Salas J.J., Venegas-Calerón M. Current advances in sunflower oil and its applications. Lipid Technology. 2009;21(4):79-82. https://doi.org/10.1002/lite.200900016.
Gedil M.A., Wye C., Berry S., Segers B., Peleman J., Jones R., Leon A., Slabaugh M.B., Knapp S.J. An integrated restriction fragment length polymorphism - amplified fragment length polymorphism linkage map for cultivated sunflower." Genome. 2001;44(2):213-221. https://doi.org/10.1139/g00-111.

Goryunov D.V., Anisimova I.N., Gavrilova V.A., Chernova A.I., Sotnikova E.A., Martynova E.U., Boldyrev S.V. et al. Association mapping of fertility restorer gene for CMS PET1 in sunflower. Agronomy. 2019;9(2):49. https://doi.org/10.3390/agronomy9020049.

Jocić S., Miladinović D., Kaya Y. Breeding and genetics of sunflower. In Sunflower. 2015;1-25. Elsevier. https://doi.org/10.1016/B978-1893997-94-3.50007-6.

Lai Z., Livingstone K., Zou Y., Church S.A., Knapp S.J., Andrews J., Rieseberg L.H. Identification and mapping of SNPs from ESTs in sunflower. TAG. Theoretical and Applied Genetics. Theoretische Und Angewandte Genetik. 2005;111(8):1532-1544. https://doi. org/10.1007/s00122-005-0082-4.

Li-Beisson Y., Shorrosh B., Beisson F., Andersson M.X., Arondel V., Bates P.D., Baud S. et al. Acyl-lipid metabolism. The Arabidopsis Book. 2010;8:e133. https://doi.org/10.1199/tab.0133.

Livaja M., Unterseer S., Erath W., Lehermeier C., Wieseke R., Plieske J., Polley A. et al. Diversity analysis and genomic prediction of sclerotinia resistance in sunflower using a new $25 \mathrm{~K}$ SNP genotyping array. Theoretical Applied Genetics. 2016;129(2):317-329. https://doi.org/10.1007/s00122-015-2629-3.

Mangin B., Casadebaig P., Cadic E., Blanchet N., Boniface M.-C., Carrère S., Gouzy J. et al. Genetic control of plasticity of oil yield for combined abiotic stresses using a joint approach of crop modelling and genome-wide association. Plant, Cell Environment. 2017; 40(10):2276-2291. https://doi.org/10.1111/pce.12961.

Masalia R.R., Temme A.A., Torralba N.L., Burke J.M. Multiple genomic regions influence root morphology and seedling growth in cultivated sunflower (Helianthus Annuus L.) under well-watered and water-limited conditions. PloS One. 2018;13(9):e0204279. https:// doi.org/10.1371/journal.pone.0204279.

Nambeesan S.U., Mandel J.R., Bowers J.E., Marek L.F., Ebert D., Corbi J., Rieseberg L.H., Knapp S.J., Burke J.M. Association mapping in sunflower (Helianthus Annuus L.) reveals independent control of apical vs. basal branching. BMC Plant Biol. 2015;15(1):84. https:// doi.org/10.1186/s12870-015-0458-9.

Popescu R., Costinel D., Dinca O.R., Marinescu A., Stefanescu I., Ionete R.E. Discrimination of vegetable oils using NMR spectroscopy and chemometrics. Food Control. Recent Advances of Food Analysis, 2015;48(February):84-90. https://doi.org/10.1016/j.foodcont.2014.04.046.

Putt E.D. Early history of sunflower. Sunflower Technology Production. 1997; agronomymonogra (sunflowertechno):1-19. https://doi. org/10.2134/agronmonogr35.c1.

Rauf S., Jamil N., Tariq S.A., Khan M., Kausar M., Kaya Y. Progress in modification of sunflower oil to expand its industrial value. Journal of the Science of Food and Agriculture. 2017;97(7):1997-2006. https://doi.org/10.1002/jsfa.8214.

Rieseberg L.H., Choi H., Chan R., Spore C. Genomic map of a diploid hybrid species. Heredity. 1993;70(3):285. https://doi.org/10.1038/ hdy.1993.41.

Talukder Z.I., Gong L., Hulke B.S., Pegadaraju V., Song Q., Schultz Q., Qi L. A high-density SNP map of sunflower derived from RADsequencing facilitating fine-mapping of the rust resistance gene R12. PLoS ONE. 2014;9(7). https://doi.org/10.1371/journal.pone. 0098628. 
Tang S., Kishore V.K., Knapp S.J. PCR-multiplexes for a genome-wide framework of simple sequence repeat marker loci in cultivated sunflower. Theoretical Applied Genetics. 2003;107(1):6-19. https://doi. org/10.1007/s00122-003-1233-0.
Vear F. Changes in sunflower breeding over the last fifty years. $O C L$. 2016;23(2):D202. https://doi.org/10.1051/ocl/2016006.

Conflict of interest. The authors declare no conflict of interest. 